\title{
Intellectual Property Rights as Development Determinants*
}

\author{
Theo S. Eicher \\ University of Washington \\ Department of Economics \\ e-mail: te@u.washington.edu \\ phone: +1 (206) 685-8082
}

Monique Newiak

Ludwig Maximilians University Munich

\begin{abstract}
While intellectual property rights (IPRs) are the key drivers of economic performance in R\&D based growth models, they have not been fully explored in empirical development studies. We introduce IPRs to this literature, using Two-Stage Least Squares Bayesian Model Averaging to address endogeneity and model uncertainty at the instrument and income stages. We show that IPRs exert similar effects as "Rule of Law" and therefore provide robust evidence that both physical and intellectual property rights are crucial development determinants. We document that unenforced IPRs exert no effect on development. Instead, it is the level of enforced IPRs that causes development.
\end{abstract}

JEL classification: 01, C1

\footnotetext{
* We thank Walter G. Park for sharing his data on Intellectual Property Rights and two referees for helpful comments. Newiak gratefully acknowledges financial support from the German Research Foundation through GRK 801. Eicher thanks Max Soto Jimènez, the Instituto de Investigaciones en Ciencias Económicas, and the Department of Economics at the University of Costa Rica for their support and hospitality during the preparation of the paper.
} 
Development determinants have long been the focus of cross-country growth regressions, which are well known to be subject to substantial model uncertainty (Barro, 1997; Durlauf et al., 2005). This model uncertainty manifests itself in the vast number of candidate regressors that have been suggested by competing strands of growth and development theories. Durlauf et al. (2005) survey no fewer than 140 growth determinants for the Handbook of Economic Growth. Therefore it is not surprising that prominent approaches to development regressions conduct robustness exercises that juxtapose literally dozens of theories and candidate regressors. ${ }^{1}$

Conspicuously absent from this entire literature is, however, one approach that includes the strength of intellectual property rights (IPRs) as a potential development determinant. $^{2}$ The omission is surprising, given that IPRs are the central driving force of economic performance in all R\&D based growth models. ${ }^{3}$ Property rights over innovations guarantee returns for investors, whose inventions constitute the ultimate engine for long term development. In sharp contrast, the protection of physical property (e.g., capital investment) has long been widely accepted as a core determinant regressor in development empirics (as measured by "Rule of Law” or “risk of expropriation”).

We follow the canonical development determinant approach of Hall and Jones (1999), Acemoglu et al. (2001), and Rodrik et al. (2004), and introduce IPRs as an additional candidate regressor into this well established line of development regressions. Conceptually we could simply add IPRs to each one of the regressions suggested by the previous literature and report the IPR significance levels. Raftery (1995) points out, however, that significance levels are inflated when coefficients are based on a single statistical model whenever the uncertainty surrounding the validity of the particular

\footnotetext{
1 Acemoglu et al. (2001) and Rodrik et al. (2004) alone introduce more than 50 candidate regressors.

${ }^{2}$ While the relationship between IPRs and growth is the subject of a voluminous literature (Gould and Gruben, 1996; Kim et al., 2012; Mohtadi and Ruediger, 2010) the effect of IPRs is usually not studied in cross-country development regressions, and never before with explicit endogeneity controls, see, e.g., Maskus and Penubarti (1995), Ginarte and Park (1997), Maskus (2000), Chen and Puttitanun (2005).

${ }^{3}$ Romer (1990) and Aghion and Howitt (1992) assume perfect IPRs; and it is easily shown that the canonical R\&D based growth model produces reduced growth and welfare with imperfect IPRs (see Eicher and Garcia-Penalosa, 2008).

${ }^{4}$ An alternative strand of the literature focuses on the effect of political institutions, see, e.g., Persson and Tabellini (2002), and Besley et al. (2005).
} 
theory is ignored. Instead, we thus utilize a statistical methodology that allows us to introduce IPRs while simultaneously addressing the profound model uncertainty that has been highlighted by the vast number of development specifications in the previous literature.

We analyze the impact of IPRs on development using Bayesian Model Averaging (BMA), which is designed to resolve model uncertainty as part of the statistical methodology. ${ }^{5}$ The added complication that development regressions posit is that their model uncertainty is not confined by development determinants, but it is also present at the instrument level. Instruments are used to address the endogeneity of development determinants and to identify their exact effects on income. Appropriate instruments have also been the subject of a voluminous literature comprised of a sizable set of alternative theories. Instead of juxtaposing particular instrument specifications in what Rodrik et al. (2004) call a "horse race" approach, we employ the Lenkoski et al. (2009) Two-Stage Least Squares BMA (2SBMA) procedure to account for model uncertainty at the development determinant and instrument levels.

To explore the effects of IPRs, we use Acemoglu et al. (2001) and Rodrik et al.’s (2004) own data and augment it with Park's (2008) IPR index. Figure 1 plots the dependent variable in Acemoglu et al. (2001)/Rodrik et al. (2004), per capita income, against Park's (2008) IPR index and reveals a clear positive relationship. We are not the first to highlight the correlation between the intellectual property rights index and development; ${ }^{6}$ we are, however, the first to address causality and model uncertainty to clarify whether better IPRs foster high incomes or whether high levels of development produce excellent IPRs. ${ }^{7}$

\section{[FIGURE 1 ABOUT HERE.]}

\footnotetext{
${ }^{5}$ See, e.g., Fernandez et al. (2001), Sala-i-Martin et al. (2004) and Papageorgiou and Masanjala (2008).

${ }^{6}$ See, e.g., Maskus and Penubarti (1995), Maskus (2000) and Ginarte and Park (1997).

${ }^{7}$ Ginarte and Park (1997) tested the latter hypothesis, but do not control for endogeneity.
} 
The 2SBMA methodology addresses the issue of causality by introducing instruments that identify the particular effect of IPRs on development. To motivate potential instruments for IPRs we follow the law and economics literature, which suggests that a particular type of legal origin provides the necessary identification for legal institutions today (see La Porta et al. 1998, 1999; Djankov, 2003).

After addressing model uncertainty and causality, we find that IPR protection, specifically patent protection, exerts an important impact on development. This impact is separate and parallel to the impact of "Rule of Law" on development. The result highlights that both dimensions of property rights protection are crucial development determinants. We can also show that the impact of IPRs is causal, as our identification strategy posits that IPRs drive income, and our tests of instrument validity support this hypothesis. In addition we show that the impact of patent rights on development depends crucially on the degree of intellectual property rights enforcement. As long as patent rights are simply "on the books” but not enforced, they are shown to exert no effect on development. It is the level of enforced patent rights that is positively correlated with development. $^{8}$ The magnitude of the impact of IPR enforcement on development is remarkable: increasing enforcement by one standard deviation causes a $42 \%$ increase in long term development. Coincidentally this effect is just about identical in magnitude to the impact of "Rule of Law" on development.

We are not the first to attempt to resolve endogeneity and identify proximate and fundamental development determinants. Alternative approaches to explain development include Mauro (1995), who first suggested ethnolinguistic fragmentation as a fundamental determinant of corruption although the subsequent literature focuses on "Rule of Law” as a more basic development determinant. Hall and Jones (1999) introduced latitude and common language as instruments for an institutional proxy that is a composite of trade, corruption and rule of law. We include these candidate instruments below and highlight the importance of the latter. La Porta et al. (2004) presented yet another "horse race" of theories, juxtaposing judicial independence vs. constitutional review; we employ their hypothesis that judicial characteristics matter in order to

${ }^{8}$ Enforcement is measured in terms of the stringency of preliminary injunctions, the existence of contributory infringement pleadings, and burden-of-proof reversals. 
motivate candidate instruments in our analysis. Lenkoski et al. (2009) apply 2SBMA to development determinants, but neglect IPRs.

We proceed as follows: Section 2 outlines the statistical approach that underlies 2SBMA and discusses theoretical properties of the technique, section 3 describes the data, section 4 discusses the key results and highlights the importance of both determinant and instrument uncertainty in the recent development literature, and section 5 concludes.

\section{$2 \quad$ Methodology}

\subsection{The Econometric Approach}

Acemoglu et al. (2001) suggest a particular theory of development, namely that private property rights (as measured by government risk of expropriation) are a crucial development determinant, and that the security of such property rights is crucially dependent on the type of colonial history a country experienced. Rodrik et al. (2004) broaden the definition of development determinants and conduct an all out "horse race" of three potential determinants (private property rights, trade, and geography) against a host of alternative theories. Acemoglu et al. (2001) and Rodrik et al. (2004) constitute the most rigorous robustness tests that have been conducted; the studies employ the largest set of potential development theories to justify and juxtapose candidate regressors.

Both studies acknowledge that the effects of proximate development determinants are endogenous and apply the 2SLS instrumental variable technique to identify the specific effect that each determinant exerts on development. A complicating factor is, however, that competing theories suggest alternative sets of different instruments. Acemoglu et al. (2001) and Rodrik et al. (2004) approach this issue by juxtaposing not only theories of development determinants, but also theories that motivate alternative instruments against another. Profound model uncertainty thus contaminates coefficient estimates at both the instrument and the determinant level.

For development accounting, Acemoglu et al. (2001) and Rodrik et al. (2004) motivate instruments with various theories, a discussion that dates back to Mauro (1995) 
and Hall and Jones (1999) who first instrumented for the quality of institutions. We focus on key sets of instruments. To identify the security of physical property rights, Acemoglu et al. (2001) propose settler mortality, which indicates whether a country was a settlement or extraction colony. Countries with the latter history are presumed to have adopted weaker property rights institutions. An alternative theory and instruments for physical property rights was proposed by Hall and Jones (1999) who suggest that the fractions of the English or European language speaking population in a country measures the colonial powers' commitment to building good property rights institutions. Implied Trade shares were also first suggested by Hall and Jones (1999) as an instrument for current physical property rights since they (or the difference between observed and implied trade) are thought to proxy for the distortions that identify insecure physical property rights.

To introduce IPRs, we are required to propose additional instruments, and we rely on a country's type of legal origin. Specifically we follow the law and economics literature, which suggests either English common law or Roman (in particular French) civil law (La Porta et al., 1998, 1999) legal origins to have a profound impact on how intellectual property rights are considered by today's legal system. David and Brierley (1985) show that corporate law and commercial laws vary systematically by legal origin, and that French legal origins (civil law) are associated with greater formalism of judicial procedures (Djankov et al. 2003) and less judicial independence (La Porta et al. 2004). The latter has been associated with better contract enforcement and greater security of property rights. Since the legal traditions were typically introduced into various countries through conquest and colonization, they are considered largely exogenous, which qualifies them as strong candidate instruments.

The idea of using the historical or colonial origins of a country's legal system as an instrument for IPRs is not new. Maskus (2000) shows that the status of being a French or UK colony explains the level of intellectual property rights as measured by the Ginarte-Park index, and Maskus and Penubarti (1995) use these indices to instrument IPRs in an analysis of trade flows. Further, legal origins are used in Maskus and Yang (2011) and in Nunn (2007) to instrument for patent protection and contract enforcement/legal quality, respectively. Admittedly there does not exist rampant model 
uncertainty at the IPR instrument level, it is through the general development accounting approach and the model uncertainty surrounding the instruments for physical property rights that the use of 2SBMA is required for a solid statistical approach.

Previous approaches to model uncertainty with potential endogeneity include Durlauf et al. (2011), who built on Tsangarides (2004) and more recently Moral-Benito (2011). The approach by Durlauf et al. (2011) selects a set of best fitting (second stage) models without controlling for endogeneity. It then matches each model with a set of instruments identified by the researcher to produce 2SLS estimates that are then averaged. The approach lacks model selection at the instrument stage and does not fully account for endogeneity in the selection stage. Moral-Benito (2011) addresses the endogeneity of the regressors with respect to time invariant heterogeneity at the country level, i.e., fixed effects. Panel approaches to address endogeneity leverage lagged dependent variables, which is not an option in cross section development accounting studies. Thus we examine the effects of intellectual and physical property rights on development by employing the Acemoglu et al. (2001) and Rodrik et al. (2004) approach while accounting for model uncertainty at the instrument and determinant stages in a 2SBMA approach.

\subsection{Statistical Foundations}

Instead of producing numerous robustness regressions, we resolve the model uncertainty using a statistical methodology that was specifically designed for that task, Two-Stage Least Squares Bayesian Model Averaging (2SBMA). 2SBMA combines the instrumental variable and BMA methodologies to process the data like a two stage estimator, while addressing model uncertainty in both stages. It is a nested approach that first determines the posterior model probabilities in the first stage via straight BMA to ascertain whether any instruments receive support from the data. Then 2SBMA model averages using the fitted values to derive second stage posterior model probabilities, means, and standard deviations. The weight of each model in the second stage depends not only on its performance, but also on the performance of the particular set of instruments that gave rise to the particular second stage model. 
In addition to resolving model uncertainty, Bayesian model averaging minimizes the sum of Type I and Type II error, the mean squared error, and generates predictive distributions with optimal predictive performance (Raftery and Zheng, 2003). 2SBMA is also consistent and it reduces the many instrument bias that is especially relevant in approaches that juxtapose a number of alternative candidate regressors (Lenkoski et al., 2009). Below we provide a sketch of the 2SBMA methodology, limiting our discussion to the properties relevant to our application and refer the interested reader to the comprehensive tutorial and derivations by Raftery et al. (1997) and Lenkoski et al. (2009) for further discussion.

The standard approach to addressing endogeneity of development determinants is to apply two-stage least squares (2SLS) and impose over-identification and instrument restrictions according to

$$
Y=\alpha+\sum_{j=1}^{p} \beta_{j} X_{j}+\eta,
$$

in which $\mathrm{Y}$ is the dependent variable, $\mathrm{X}$ is a vector of candidate regressors which is comprised of a vector of $\mathrm{W}$ endogenous and $\mathrm{D}$ exogenous variables. Reverse causality is of utmost interest in development regressions. Are countries rich because they have good institutions or property rights, or are property rights strong in countries that are sufficiently wealthy to maintain them?

In the presence of endogeneity, the determination of $\mathrm{W}$ leads to inconsistent estimates of the entire coefficient in (1). The 2SLS estimator solves the consistency problem, but relies on the existence of a set of instruments, $\mathrm{Z}$, which are independent of $\mathrm{Y}$, given the vector of covariates $\mathrm{X}$. To identify the effect of $\mathrm{W}$ on $\mathrm{Y}$, the researcher must suggest a set of instruments, $\mathrm{Z}$, such that

$$
W=\delta+\theta_{Z} Z+\theta_{D} D+\varepsilon .
$$

The IV estimates derived in a second stage by using the fitted values from the first stage (2) are consistent only if the conditional independence assumptions are valid. Theories seldom present clear-cut instruments that have both strong explanatory power on the endogenous variables and unquestionable conditional independence properties in relation 
to the dependent variable. Over-identification tests such as the one proposed by Sargan (1958) help verify the validity of the instrument assumptions.

The 2SBMA setup can be concisely summarized as follows. Let $\Delta$ be a quantity of interest and $\mathrm{M}$ the set of potential models that is comprised of I individual models in the first stage. The posterior distribution of $\Delta$ given the data, $\mathrm{D}$, is given by the weighted average of the predictive distribution under each model,

$$
\operatorname{pr}(\Delta \mid D)=\sum_{i=1}^{I} \operatorname{pr}\left(\Delta \mid M_{i}, D\right) \pi_{i}
$$

in which $\operatorname{pr}\left(\Delta \mid M_{i}, D\right)$ is the predictive distribution and the model weight is

$$
\pi_{i}=\operatorname{pr}\left(M_{i} \mid D\right) \propto \int \operatorname{pr}\left(D \mid \theta_{i}, M_{i}\right) \mu\left(\theta_{i}\right) d \theta_{i} \gamma\left(M_{i}\right)
$$

The model weight is thus comprised of the posterior probability for model $\mathrm{M}_{\mathrm{i}}$ and the prior densities for parameters and models, $\mu\left(\theta_{i}\right)$ and $\gamma\left(M_{i}\right)$, respectively. ${ }^{9}$ Intuitively, this implies that a model's weight is proportional to its relative efficiency in describing the data.

Posterior model probabilities are also the weights used to establish the posterior means and variances

$$
\begin{gathered}
\hat{\theta}^{\text {BMA }}=\sum_{i \in M}^{I} \hat{\theta}_{i} \pi_{i}, \\
\hat{\sigma}^{2^{B M A}}=\sum_{i \in M}^{I} \pi_{i} \hat{\sigma}_{i}^{2}+\sum_{i \in M}^{I} \pi_{i}\left(\hat{\theta}_{i}-\hat{\theta}_{i}^{B M A}\right)^{2} .
\end{gathered}
$$

The BMA posterior mean is thus the weighted sum of all posterior means, where the weight is the quality of the model that generated a particular coefficient. The posterior variance is the sum of the weighted variance for each model plus a second term that indicates how much the estimates differ across models. To provide economically meaningful coefficient estimates we condition the posterior mean and variance on

\footnotetext{
${ }^{9}$ An additional issue to be considered is potential functional form misspecification, which we do not address in our approach. Previous approaches to model averaging that include both semi parametric and non parametric methods are Tsangarides (2004), Chen, Mirestean, and Tsangarides (2009), Mirestean and Tsangarides (2009), Moral-Benito (2009), and Ghosal and Lember (2008). We leave the thorny issue of developing a statistical theory of both endogeneity and functional form uncertainty to future research.
} 
whether a regressor is included in the model. By summing the posterior model probabilities over all models that include a candidate regressor, we obtain the posterior inclusion probability

$$
\operatorname{pr}\left(\hat{\theta}_{i} \neq 0 \mid D\right)=\sum_{i \in M} \pi_{i} .
$$

The posterior inclusion probability of a regressor is the probability that a variable is included in the true model. It provides a probability statement regarding the importance of a regressor that directly addresses the researchers' prime concern: what is the probability that the coefficient has a non-zero effect on the dependent variable? The posterior inclusion probability thus also carries an important interpretation that goes beyond the information contained in standard p-values.

General rules developed by Jeffreys (1961) and refined by Kass and Raftery (1995) stipulate effect-thresholds for posterior probabilities. Posterior probabilities < $50 \%$ are seen as evidence against an effect, and the evidence for an effect is either weak, positive, strong, or decisive for posterior probabilities ranging from 50-75\%, 75-95\%, 95$99 \%$, and $>99 \%$, respectively. In our analysis, we refer to a regressor as "effective" if its posterior inclusion probability exceeds $50 \%$.

To address endogeneity, 2SBMA first determines the posterior model probabilities as outlined above as well as the first stage fitted values, $\widetilde{w}_{i}$, for each model $\mathrm{M}_{\mathrm{i}}$. Denoting the set of $j$ second stage models as L, 2SBMA then uses the fitted values to derive second stage posterior probabilities and estimates, $v_{j}\left(\widetilde{w}_{i}\right)$ and $\hat{\beta}_{j}\left(\tilde{w}_{i}\right)$ to obtain the posterior mean

$$
\hat{\beta}^{2 S L S B M A}=\sum_{i \in M}^{I} \sum_{j \varepsilon L}^{J} v_{j}\left(\tilde{w}_{i}\right) \pi_{i} \hat{\beta}_{j}\left(\tilde{w}_{i}\right) .
$$

The posterior mean consists of the combination of weighted fitted values from the first stage models and the weighted posteriors means of the second stage models. The model weight, or the quality of the first stage instrumentation thus influences the overall model weight of a second stage coefficient. The posterior variance and inclusion probability are then 


$$
\begin{gathered}
\hat{\sigma}^{2 \text { 2SLSBMA }}=\sum_{i \in M}^{I} \pi_{i}\left(\sum_{j \in L}^{J} v_{j} \sigma_{j}^{2}+\sum_{j \in L}^{J} v_{j}\left(\hat{\beta}_{j}-\bar{\beta}\right)^{2}\right)+\sum_{i \in M}^{I} \pi_{i}\left(\bar{\beta}_{i}-\hat{\beta}_{i}^{2 \text { 2SLSBMA }}\right)^{2} \\
\operatorname{pr}\left(\hat{\beta}_{j} \neq 0 \mid D\right)=\sum_{i \in M} \sum_{j \varepsilon L} v_{j} \pi_{i},
\end{gathered}
$$

in which $\bar{\beta}$ is the model averaged estimate for a given first stage model, $\mathrm{M}_{\mathrm{i}}$. The 2SBMA variance has a similar interpretation as the BMA variances. ${ }^{10}$ The first term is the average of BMA variances associated with the first stage models, and the second term represents the variation of a given first stage model's BMA estimates relative to the overall 2SBMA estimate.

Previous approaches that outline Bayesian instrumental variable methods are provided by Geweke (1996) and Kleibergen and Zivot (2003). There is also a literature that attempts to “derive” IV, in some cases using automatic, information-theory-based methods to avoid explicit priors (see Kitamura and Stutzer (1997), Zellner et al. (1997), and Kim (2002)). Related work by Chao and Phillips (1998) pursues the use of Jeffrey’s priors, which are another automatically generated class of priors. We assume that the model prior is uniform, and simplify matters by using the BIC approximation or Unit Information Prior (UIP) that has been motivated for BMA applications by Kass and Wasserman (1995) and Raftery (1995). The UIP is a normal prior with a mean centered at the maximum likelihood estimate and a variance equal to the inverse of the average information contained in one observation. Lenkoski et al. (2009) show that the two-stage UIP can be considered a proper analogue of the Kleibergen and Zivot (2003) prior. To explore the model space, we utilize the Leaps and Bounds algorithm developed by Furnival and Wilson (1974), which guarantees that the best model is included in among those averaged. For similar priors the algorithm can be shown to produce identical results as Monte Carlo Markov Chain Model Composition (MC3, Madigan and York, 1995).

\section{Data}

10 We follow 2SLS theory, which requires that (a) all regressors in the second-stage are included in the first stage. Since we have two first-stages, theory requires all second stage regressors are included in both first stages. Both stages are subject to model averaging; (b) when more than one endogenous regressor is present, theory requires that the instruments for endogenous regressor A are also included in the first-stage of regressor B; (c) models with only the constant are not considered in the first stage. 
Our data was collected from four major sources. Acemoglu et al. (2001) provide data on settler mortality and religion, Park (2008) provides the IPR index, which is in fact an index of patent protection, and La Porta et al. (1998) provide data on the legal origins of a country. All other variables suggested in the comprehensive robustness approach are obtained from Rodrik et al. (2004). Acemoglu et al.’s (2001) sample covers 64 countries, but the combination with IPR data limits our sample to 54 observations.

Table 1 provides the key descriptive statistics for all variables. For example, GDP per capita ranges from $\$ 519$ (Tanzania) to $\$ 27,806$ (US) with a mean of $\$ 4,825$, and Rule of Law ranges from 1.71 (New Zealand) to -1.49 (Angola), with a mean of -0.28. Park's patent index is the sum of five equally weighted sub-indices (patent length, scope, enforcement, the protection from loss of patent rights and membership in patent treaties). ${ }^{11}$ It evaluates the strength of a country's patent system on a scale of 0 (poor patent system) to 5 (strong patent system) with US (4.48) being the strongest and Angola (0.0) the weakest. Patent enforcement is measured on a scale of 0 to 1 scale where 1 is obtained if a country has all of the following enforcement mechanisms: preliminary injunctions, contributory infringement pleadings and burden-of-proof reversals.

\section{Quantifying the Effects of IPRs on Development}

This section reports the results of the 2SBMA estimation that introduces IPRs to the canonical development regressions by Acemoglu et al. (2001) and Rodrik et al. (2004) and resolves model uncertainty as part of the statistical procedure. We commence with the results for the aggregate patent index. Columns 2-4 and 5-6 in Table 2 reveal that our instrument strategy provides two effective instruments for patents (fraction of English speaking population in a country and French legal origin) and that physical property rights are also well identified. The Bayesian Sargan test (see Lenkoski et al., 2009) confirms that the exogeneity condition is fulfilled and the instruments are not correlated with the error term in the equation of interest. In other words, the legal and colonial history instrument regressors do exert an effect on development, but not directly, only indirectly through their impact on IPRs. We can thus be confident that the endogeneity of

\footnotetext{
${ }^{11}$ This index is an updated version of the Ginarte and Park (1997) index, see Park (2008).
} 
IPRs has been addressed successfully and are able to discuss causal effects of IPRs on development.

The impact of the aggregate patent index on development is, however, disappointing: The aggregate patent index does not surpass the effectiveness threshold. Instead, "Rule of Law" and geographic variables, such as tropics, malaria, and the SouthEast Asia dummy show inclusion probabilities that are significantly larger than $50 \%$. One hypothesis could be that the weak effect of the aggregate patent index reflects the sizable number of developing countries that achieve high marks for the breadth of their patent laws, but whose intellectual property rights laws are not well enforced.

By disaggregating the patent index, we find that the average patent duration is largely identical for developing and developed countries. In contrast, a number of developing countries exhibit a dismal score for the enforcement of their stringent patent rights. With an average patent enforcement index of 0.11, developing countries' enforcement mechanisms are almost eight times weaker than the average protection afforded by developed economies.

To test our hypothesis formally, we replace the aggregate patent index by the patent enforcement index and reestimate the above specification. With three valid instruments (settler mortality, fraction of population speaking English, and French legal origin), patent enforcement is well identified. The result of the Sargan test confirms the exogeneity of the instruments, which allows us to discuss causal results. Table 3 reports strong positive effects of the enforcement of intellectual property rights on development. Given the coefficient estimates in column 9, we find that a one standard deviation increase in patent enforcement increases income by $42.0 \%{ }^{12}$. This magnitude is impressive given that a one standard deviation increase in "Rule of Law", the key regressor in the previous literature, increases income by a similar magnitude (by $41.7 \%)^{13}$. This result strongly suggests that both dimensions of property protection,

\footnotetext{
12 The dependent variable (income per capita) is measured in logs and patent enforcement enters the regression in levels. Thus the effect of an increase in patent enforcement by one standard deviation is 1.6 times 0.26 (see table 1 ) or about $42 \%$.

${ }^{13}$ Rule of Law enters the regression also in levels, so that increasing "Rule of Law" by one standard deviation increases income per capita by 0.524 times 0.80 (see table 1 ), or about $42 \%$.
} 
physical and intellectual, are crucial for development and that a simultaneous increase in the two dimensions by one standard deviation more than doubles income per capita. ${ }^{14}$

These figures, do, of course, not imply that a change in the physical or intellectual property rights is possible over night as many of the institutional features of a country are highly persistent - and this is true for "Rule of Law" even more than for intellectual property rights. Moreover, a change in physical and intellectual property rights cannot, by definition, immediately affect the long-run development of a country so that the magnitudes of the institutional effects on development do not have immediate policy implications. Instead these figures tell us that a large part of the income differences we observe today can be explained via how physical and intellectual property is treated in different countries.

Apart from highlighting the impact of the two dimensions of property protection on development, our results also emphasize the importance of accounting for model uncertainty at both the instrument and income stages. The approach allows us to augment the findings by Rodrik et al. (2004) and Acemoglu et al. (2001). Our approach discovers, for example, additional income determinants: While Rodrik et al. (2004) and Acemoglu et al. (2001) find at best weak direct evidence of geography on development we find strong effects for geographic variables that influence the level of development (e.g., Latin America, East Asia, tropics, and malaria). ${ }^{15}$ These results are consistent with the results obtained by Lenkoski et al. (2009) who account for model uncertainty by using 2SBMA. In line with the results by Rodrik et al. (2004), we also find that trade does not surpass the effectiveness threshold. Our first stage results confirm those of Lenkoski et al. (2009) and Albouy (2008) in that settler mortality is not an effective instrument for "Rule of Law" in contrast to the findings of Rodrik et al. (2004) and Acemoglu et al. (2001). However, we do find that settler mortality serves as a strong instrument for the intellectual property dimension of institutions as its inclusion probability for patent enforcement is almost 90\%. All other results conform to Lenkoski et al. (2009), Rodrik et

\footnotetext{
${ }^{14}$ Our results are robust to the inclusion of alternative measures of IPRs and IPR enforcement. In regressions that are available from the authors, we introduce sub-indices for duration, coverage and protection from loss of rights. None of these indices changed our results or surpassed effective thresholds.

${ }^{15}$ Kourtellos et al. (2010) previously challenged Rodrik et al.’s (2004) results on the basis of parameter heterogeneity.
} 
al. (2004), and Hall and Jones (1999), in the sense that regressors which proxy for common languages are shown to be excellent instruments for institutions.

\section{Conclusion}

The literature that attempts to isolate development determinants has long focused on the effects of physical property rights protection as a key determinant of the observed differences in per capita incomes. Rule of Law (Rodrik et al., 2004) or Risk of Government Expropriation (Acemoglu et al., 2001) have previously been identified as crucial institutional development determinants. Theoretical models of development also highlight, however, the importance of intellectual property rights, which we introduce to the development empirics literature in our paper.

Cross-country growth and development regressions are well known to suffer from substantial model uncertainty, and numerous candidate regressors and theories have been proposed by the voluminous literature in outright "horse races" (Rodrik et al., 2004; La Porta et al., 2004). Not only is the uncertainty about development determinants substantial, but theories which suggest instruments to resolve endogeneity are equally abundant. In this paper, while introducing IPRs into the cross country development literature, we account for endogeneity of the development determinants and address model uncertainty at the income determinant and instrument levels using Two-Stage Least Square Bayesian Model Averaging (2SBMA).

We find that intellectual property rights exert a strong impact on development if they are properly enforced. The important insight is thus that both intellectual and physical property rights are crucial determinants of cross-county income differences. Interestingly, our results suggest that the two dimensions of property rights protection hold equally strong explanatory power: a one standard deviation increase in "Rule of Law" increases per capita income by $42 \%$, and this effect is identical to the impact of a one standard deviation increase in patent enforcement, which is also estimated to raise per capita income by the same amount. In line with previous studies, we also find evidence for an effect of geographical variables (as malaria and tropics) on development. We conclude from the data that the effective protection of both physical and intellectual 
property rights, along with geography, are the key determinants of a country's economic development. 
Figure 1: Development and Intellectual Property Rights

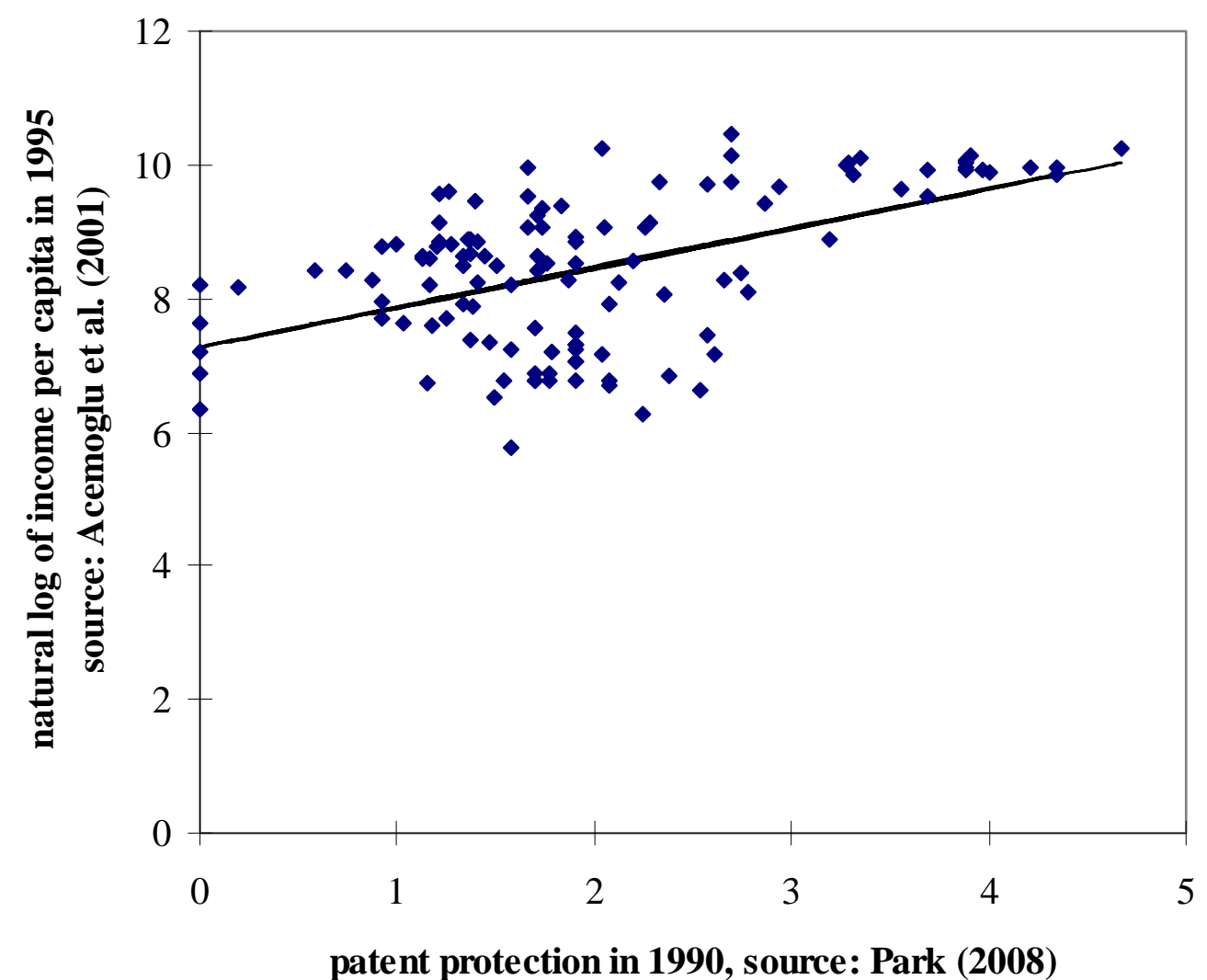

patent protection in 1990, source: Park (2008) 
Table 1: Descriptive Statistics and Data Sources

\begin{tabular}{|c|c|c|c|c|c|}
\hline Variable & Max & Min & Mean & StDev & meaning, source \\
\hline lcgdp95 & 10.23 & 6.25 & 7.99 & 0.97 & " natural log of GDP per capita in PPP in 1995, RST (2004), orig.: PWT, Mark 6. \\
\hline gdp95 & 27806.08 & 519.00 & 4824.67 & 5659.47 & GDP per capita in 1995 , same as above \\
\hline rule & 1.71 & -1.49 & -0.28 & 0.80 & Rule of Law, RST (2004), originally: Kaufmann, Kraay, and Zoido-Lobaton (2002) \\
\hline logem4 & 7.99 & 2.15 & 4.79 & 1.19 & Settler Mortality, AJR (2001) \\
\hline logfrankrom & 3.74 & 0.94 & 2.49 & 0.63 & Nat. log of predicted trade shares, RST (2004), originally: Frankel and Romer (1999) \\
\hline engfrac & 0.95 & 0.00 & 0.08 & 0.22 & Fraction of pop. speaking English, RST (2004), originally: Hall and Jones (1999) \\
\hline eurfrac & 1.00 & 0.00 & 0.32 & 0.41 & Fraction of pop. speaking English, French, German, Portuguese or Spanish, RST (2004 \\
\hline legor_fr & 1.00 & 0.00 & 0.68 & 0.46 & 1 if origins of the legal system are French, La Porta et al. (1998) \\
\hline disteq & 45.00 & 0.00 & 15.82 & 12.03 & Distance from Equator, RST (2004) \\
\hline laam & 1.00 & 0.00 & 0.34 & 0.47 & 1 if country belongs to Latin America or the Caribbean, RST (2004) \\
\hline safrica & 1.00 & 0.00 & 0.41 & 0.49 & 1 if country belongs to Sub-Saharan Africa, RST (2004) \\
\hline catho80 & 96.60 & 0.10 & 44.23 & 37.42 & 1 if population is predominantly Catholic, AJR (2001) \\
\hline muslim80 & 99.40 & 0.00 & 23.95 & 33.75 & 1 if population is predominantly Muslim, AJR (2001) \\
\hline protmg80 & 58.40 & 0.00 & 11.04 & 13.99 & 1 if population is predominantly Protestant, AJR (2001) \\
\hline tropics & 1.00 & 0.00 & 0.73 & 0.41 & percentage of tropical land area, RST (2004), orig.: Gallup and Sachs (1998) \\
\hline access & 1.00 & 0.00 & 0.18 & 0.37 & 1 for countries without access to the sea, RST (2004) \\
\hline oil & 1.00 & 0.00 & 0.11 & 0.29 & 1 if country is major oil exporter, RST (2004) \\
\hline frstarea & 1.00 & 0.00 & 0.17 & 0.29 & Prop. of land $>5$ frost-days/month in winter, RST (2004) \\
\hline frstdays & 29.68 & 0.02 & 3.42 & 5.91 & Avg. number of frost-days/month in winter, RST (2004) \\
\hline malfal94 & 1.00 & 0.00 & 0.44 & 0.44 & Malaria index for 1994, RST (2004), originally: Gallup and Sachs (1998) \\
\hline meantemp & 29.30 & -0.20 & 22.70 & 5.09 & Average temperature in Celsius, RST (2004) \\
\hline lcopen & 4.64 & 2.55 & 3.76 & 0.47 & natural log of nominal openness, RST (2004), originally: PWT, Mark 6 \\
\hline asiae & 1.00 & 0.00 & 0.07 & 0.23 & 1 if country belongs to South-East Asia, RST (2004) \\
\hline pat_1990 & 4.68 & 0.00 & 1.74 & 0.81 & Patent index (0-5 scale, zero=weak, $1=$ strong), Park (2008) \\
\hline enf_1990 & 1.00 & 0.00 & 0.17 & 0.26 & Patent enforcement index (0=weak, $1=$ =strong), Park (2008) \\
\hline
\end{tabular}


Table 2: Instrumented Effects of Property Rights on Development

\begin{tabular}{|c|c|c|c|c|c|c|c|c|c|}
\hline & \multicolumn{3}{|c|}{ Patent Protection } & \multicolumn{3}{|c|}{ Rule of Law } & \multicolumn{3}{|c|}{ Income } \\
\hline & $\begin{array}{l}\text { Incl. } \\
\text { Prob. }\end{array}$ & $\begin{array}{c}\text { Posterior } \\
\text { Mean }\end{array}$ & $\begin{array}{c}\text { Posterior } \\
\text { StDev. }\end{array}$ & $\begin{array}{l}\text { Incl. } \\
\text { Prob. }\end{array}$ & $\begin{array}{c}\text { Posterior } \\
\text { Mean }\end{array}$ & $\begin{array}{c}\text { Posterior } \\
\text { StDev. }\end{array}$ & $\begin{array}{l}\text { Incl. } \\
\text { Prob. }\end{array}$ & $\begin{array}{c}\text { Posterior } \\
\text { Mean }\end{array}$ & $\begin{array}{c}\text { Posterior } \\
\text { StDev. }\end{array}$ \\
\hline \multicolumn{10}{|l|}{ INSTRUMENTS } \\
\hline Engl Lang Frac & 100.0 & 1.807 & 0.536 & 9.3 & 0.839 & 0.531 & & & \\
\hline French Legal Orig & 55.6 & -0.424 & 0.206 & 11.8 & 0.203 & 0.160 & & & \\
\hline Euro Lang Frac & 1.7 & -0.633 & 0.458 & 98.7 & 1.298 & 0.294 & & & \\
\hline Implied Trade Share & 26.8 & 0.240 & 0.148 & 3.5 & 0.110 & 0.139 & & & \\
\hline Settler Mortality & 8.4 & -0.144 & 0.118 & 8.1 & 0.095 & 0.077 & & & \\
\hline \multicolumn{10}{|c|}{ DEVELOPMENT DETERMINANTS } \\
\hline South-East Asia & & & & & & & 84.9 & 1.043 & 0.472 \\
\hline Rule of Law & & & & & & & 80.7 & 0.702 & 0.260 \\
\hline Malaria 1994 & & & & & & & 75.9 & -0.716 & 0.307 \\
\hline Oil & & & & & & & 70.1 & 0.572 & 0.277 \\
\hline Tropics & & & & & & & 58.0 & -0.592 & 0.325 \\
\hline Muslim & & & & & & & 56.3 & -0.006 & 0.003 \\
\hline Sub-Saharan Africa & & & & & & & 51.7 & -0.585 & 0.318 \\
\hline Catholic & & & & & & & 47.4 & 0.008 & 0.004 \\
\hline Trade & & & & & & & 34.1 & 0.252 & 0.192 \\
\hline Patent Protection & & & & & & & 29.4 & 0.285 & 0.390 \\
\hline Latin America & & & & & & & 18.4 & 0.433 & 0.394 \\
\hline No Sea Access & & & & & & & 13.3 & -0.233 & 0.210 \\
\hline Distance Equator & & & & & & & 12.2 & -0.016 & 0.016 \\
\hline Mean Temperature & & & & & & & 8.8 & -0.012 & 0.034 \\
\hline Frost Area & & & & & & & 6.9 & 0.351 & 0.417 \\
\hline Frost Days & & & & & & & 4.0 & 0.006 & 0.026 \\
\hline Protestant & & & & & & & 0.9 & -0.001 & 0.008 \\
\hline Bayes Sargan P-value & & & & & & & 0.59 & & \\
\hline
\end{tabular}


Table 3: Instrumented Effects of Patent Enforcement on Development

\begin{tabular}{|c|c|c|c|c|c|c|c|c|c|}
\hline & \multicolumn{3}{|c|}{ Patent Enforcement } & \multicolumn{3}{|c|}{ Rule of Law } & \multicolumn{3}{|c|}{ Income } \\
\hline & $\begin{array}{l}\text { Incl. } \\
\text { Prob. }\end{array}$ & $\begin{array}{c}\text { Posterior } \\
\text { Mean }\end{array}$ & $\begin{array}{c}\text { Posterior } \\
\text { StDev. }\end{array}$ & $\begin{array}{l}\text { Incl. } \\
\text { Prob. }\end{array}$ & $\begin{array}{c}\text { Posterior } \\
\text { Mean }\end{array}$ & $\begin{array}{c}\text { Posterior } \\
\text { StDev. }\end{array}$ & $\begin{array}{c}\text { Incl. } \\
\text { Prob. }\end{array}$ & $\begin{array}{c}\text { Posterior } \\
\text { Mean }\end{array}$ & $\begin{array}{c}\text { Posterior } \\
\text { StDev. }\end{array}$ \\
\hline \multicolumn{10}{|l|}{ INSTRUMENTS } \\
\hline Engl Lang Frac & 100.0 & 0.647 & 0.162 & 9.3 & 0.839 & 0.531 & & & \\
\hline Settler Mortality & 89.5 & -0.081 & 0.033 & 8.1 & -0.095 & 0.077 & & & \\
\hline French Legal Orig & 51.5 & -0.114 & 0.060 & 11.8 & -0.203 & 0.160 & & & \\
\hline Euro Lang Frac & 21.5 & 0.143 & 0.088 & 98.7 & 1.298 & 0.294 & & & \\
\hline Impl. Trade Share & 0.4 & -0.042 & 0.042 & 3.5 & -0.110 & 0.139 & & & \\
\hline \multicolumn{10}{|c|}{ DEVELOPMENT DETERMINANTS } \\
\hline South-East Asia & & & & & & & 90.9 & 0.987 & 0.317 \\
\hline Oil & & & & & & & 75.6 & 0.566 & 0.257 \\
\hline Patent Enforcement & & & & & & & 78.9 & 1.600 & 0.704 \\
\hline Malaria 1994 & & & & & & & 75.1 & -0.603 & 0.267 \\
\hline Tropics & & & & & & & 65.5 & -0.591 & 0.295 \\
\hline Rule of Law & & & & & & & 61.2 & 0.524 & 0.284 \\
\hline Latin America & & & & & & & 51.8 & 0.658 & 0.314 \\
\hline Catholic & & & & & & & 38.2 & 0.008 & 0.003 \\
\hline Trade & & & & & & & 31.8 & 0.257 & 0.170 \\
\hline Sub-Saharan Africa & & & & & & & 22.2 & -0.544 & 0.345 \\
\hline Mean Temperature & & & & & & & 18.9 & -0.026 & 0.029 \\
\hline Muslim & & & & & & & 17.5 & -0.005 & 0.003 \\
\hline No Sea Access & & & & & & & 13.5 & -0.237 & 0.186 \\
\hline Frost Area & & & & & & & 7.8 & 0.490 & 0.389 \\
\hline Distance Equator & & & & & & & 7.5 & -0.013 & 0.015 \\
\hline Frost Days & & & & & & & 6.9 & 0.020 & 0.020 \\
\hline Protestant & & & & & & & 0.5 & -0.003 & 0.007 \\
\hline Bayes Sargan P-value & & & & & & & 0.55 & & \\
\hline
\end{tabular}




\section{References}

Acemoglu, Daron, Simon Johnson, and James A. Robinson (2001) “The Colonial Origins of Comparative Development: An Empirical Investigation," American Economic Review 91, 1369-1401

Aghion, Philippe, and Peter Howitt (1992) "A Model of Growth through Creative Destruction,” Econometrica 60, 323-51

Albouy, David Y. (2008) "The Colonial Origins of Comparative Development: An Empirical Investigation: Comment," Forthcoming, American Economic Re view

Barro, Robert J. (1997) "Determinants of Economic Growth: A Cross-Country Empirical Study,” The MIT Press, (Cambridge, MA)

Besley, Timothy, Torsten Persson, and Daniel Sturm (2005) "Political Competition and Economic Performance: Theory and Evidence from the United States,” LSE WP, presented at ASSA meetings

Chao, John C., and Peter C. B. Phillips (1998) "Posterior Distributions in Limited Information Analysis of the Simultaneous Equations Model Using the Jeffreys Prior," Journal of Econometrics 87, 49-86

Chen, Huigang, Alin Mirestean, and Charalambos G. Tsangarides (2009) "Limited Information Bayesian Model Averaging for Dynamic Panels with Short Time Periods," IMF WP 09/74

Chen, Yongmin, and Thitima Puttitanun (2005) "Intellectual Property Rights and Innovation in Developing Countries," Journal of Development Economics 78, 474-93

David, René, and John E. C. Brierley (1985) "Major Legal Systems in the World Today," (London: Stevens \& Sons).

Deardorff, Alan V. (1992) “Welfare Effects of Global Patent Protection,” Economica 59, 35-51

Dinopoulos, Elias, and Paul Segerstrom (2010) "Intellectual Property Rights, Multinational Firms, and Economic Growth,” Journal of Development Economics 92, $13-27$

Djankov, Simeon, Rafael La Porta, Florencio López-de-Silanes, and Andrei Shleifer (2003) “Courts,” Quarterly Journal of Economics 118, 453-517

Durlauf, Steven N., Paul A. Johnson, and Jonathan R.W. Temple (2005) "Growth Econometrics," in Handbook of Economic Growth, Elsevier (Amsterdam NorthHolland), 555-677

Durlauf, Steven N., Andros Kourtellos, and Chih Ming Tan (2008) "Are Any Growth Theories Robust?” Economic Journal 118, 329-46

Durlauf, Steven N., Andros Kourtellos, and Chih Ming Tan (2011) "Is God in the details? A reexamination of the role of religion in economic growth" Journal of Applied Econometrics published online: APR 2011 DOI:10.1002/jae.1245

Eicher, Theo S., and Cecilia Garcia-Penalosa (2008) "Endogenous Strength of Intellectual Property Rights,” European Economic Review 52, 237-58

Fernandez, Carmen, Eduardo Ley, and Mark F. J. Steel (2001) "Model Uncertainty in Cross-Country Growth Regressions,” Journal of Applied Econometrics 16, 563-76 
Frankel, Jeffrey A., and David Romer (1999) “Does Trade Cause Growth?” American Economic Review 89, 379-99

Furnival, George M., and Robert W. Wilson (1974) "Regression by leaps and bounds," Technometrics 16, 499-511

Gallup, John Luke, and Jeffrey D. Sachs (1998) “The Economic Burden of Malaria,” Center for International Development, Harvard University, mimeo

Geweke, John (1996) “Bayesian Reduced Rank Regression in Econometrics,” Journal of Econometrics 75, 121-46

Ginarte, Juan C., and Walter G. Park (1997) "Determinants of Patent Rights: A CrossNational Study,” Research Policy 26, 283-301

Gould, David M., and William C. Gruben (1996) "The Role of Intellectual Property Rights in Economic Growth,” Journal of Development Economics 48, 323-50

Ghosal, Subhashis, Jüri Lember, and Aad van der Vaart (2008) "Nonparametric Bayesian model selection and averaging,” Electronic Journal of Statistics 2, 63-89

Hall, Robert E., and Charles I. Jones (1999) "Why Do Some Countries Produce So Much More Output Per Worker Than Others?” Quarterly Journal of Economics 114, 83-116

Helpman, Elhanan (1993) “Innovation, Imitation, and Intellectual Property Rights," Econometrica 61, 1247-80

Jeffreys, Harold (1961) “Theory of Probability,” Oxford, U.K.: Clarendon Press

Kass, Robert E., and Adrian E. Raftery (1995) "Bayes Factors and Model Uncertainty," Journal of the American Statistical Association 90, 773-95

Kass, Robert E. and Wasserman, L. (1995) “A Reference Test for Nested Hypotheses with Large Samples,” Journal of the American Statistical Association 90, 928-34

Kaufmann, Daniel, Aart Kraay, and Pablo Zoido-Lobatón (2002) “Governance Matters II - Updated Indicators for 2000/01,” World Bank Policy Research Department WP 2772

Kim, Yee Kyoung, Keun Lee, Walter G. Park, and Kineung Choo (2012) “Appropriate Intellectual Property Protection and Economic Growth in Countries at Different Levels of Development," Research Policy 41, 358-75

Kim, Jae-Young (2002) “Limited information likelihood and Bayesian analysis,” Journal of Econometrics 107, 175-93

Kitamura, Yuichi, and Michael Stutzer (1997) “An Information-Theoretic Alternative to Generalized Method of Moments Estimation,” Econometrica 65, 861-74

Kleibergen, Frank, and Eric Zivot (2003) "Bayesian and Classical Approaches to Instrumental Variable Regression,” Journal of Econometrics 114, 29-72

Kourtellos, Andros, Thanasis Stengos and Chih Ming Tan (2010): "Do Institutions Rule? The Role of Heterogeneity in the Institutions vs. Geography Debate," Economics Bulletin 30, 1710-19

La Porta, R., F. López-de-Silanes, C. Pop-Eleches, and A. Shleifer (2004) "Judical Checks and Balances,” Journal of Political Economy 112, 445-70

La Porta, Rafael, Florencio López-de-Silanes, Andrei Shleifer, and Robert Vishny (1998) "Law and Finance," Journal of Political Economy 106, 1113-55 
La Porta, Rafael, Florencio López-de-Silanes, Andrei Shleifer, and Robert Vishny (1999) “The Quality of Government," Journal of Law, Economics and Organization 15, 222 79

Lenkoski, Alex, Theo S. Eicher, and Andrian E. Raftery (2009) “Two-Stage Model Averaging in Endogenous Variable Models,” Forthcoming Econometric Reviews

Lorenczik, Christian, and Monique Newiak (2011) "Imitation and Innovation Driven Development under Imperfect Intellectual Property Rights,” University of Munich mimeo

Madigan, David, and Jeremy York (1995) "Bayesian Graphical Models for Discrete Data," International Statistical Review 63, 215-32

Maskus, Keith E. (2000) “Intellectual Property Rights in the Global Economy,” Institute for International Economics (Washington, DC)

Maskus, Keith E., and Mohan Penubarti (1995) "How Trade-Related are Intellectual Property Rights?” Journal of International Economics 39, 227-48

Maskus, Keith E., and Lei Yang (2011) “Patent Reforms and Export Specialization,” University of Colorado Working Paper

Masanjala, Winford H., and Chris Papageorgiou (2008) "Rough and Lonely Road to Prosperity: A Reexamination of the Sources of Growth in Africa using Bayesian Model Averaging," Journal of Applied Econometrics 23, 671-82

Masters, William A., and Margaret S. McMillan (2001) "Climate and Scale in Economic Growth,” Journal of Economic Growth 6, 167-86

Mauro, Paolo (1995) “Corruption and Growth,” Quarterly Journal of Economics 110, 681- 712

Mirestean, Alin, and Charalambos Tsangarides (2009) "Growth Determinants Revisited," IMF WP 09/268

Moral-Benito, Enrique (2011) "Determinants of Economic Growth: A Bayesian Panel Data Approach," Review of Economics and Statistics, forthcoming

Nunn, Nathan (2007) "Relationship-Specificity, Incomplete Contracts, and the Pattern of Trade,” Quarterly Journal of Economics 122, 569-600

Park, Walter G. (2008) “International Patent Protection: 1960-2005,” Research Policy 37, 761-66

Persson, Torsten, and Guido Tabellini (2002) "Political Economics: Explaining Economic Policy,” The MIT Press (Cambridge, MA)

Raftery, Adrian E. (1995) "Bayesian Model Selection in Social Research,” Sociological Methodology 25, 111-63

Raftery, Adrian E., David Madigan, and Jennifer Hoeting (1997) "Bayesian Model Averaging for Linear Regression Models," Journal of the American Statistical Association 92, 179-91

Raftery, Adrian E., and Yingye Zheng (2003) "Discussion: Performance of Bayesian Model Averaging,” Journal of the American Statistical Association 98, 931-38

Rodrik, Dani, Arvind Subramanian and Francesco Trebbi (2004) “Institutions Rule: The Primacy of Institutions over Geography and Integration in Economic Development," Journal of Economic Growth 9, 131-65 
Romer, Paul M. (1990) “Endogenous Technological Change," Journal of Political Economy 98, S71-S102

Sala-i-Martin, Xavier, Gernot Doppelhofer, and Ronald I. Miller (2004) "Determinants of Long-Term Growth: A Bayesian Averaging of Classical Estimates (BACE) Approach,” American Economic Review 94, 813-35

Sargan, J. D. (1958) "The Estimation of Economic Relationships using Instrumental Variables,” Econometrica 26, 393-415

Tsangarides, Charalambos G. (2004) “A Bayesian Approach to Model Uncertainty,” IMF WP 0468

Zellner, Arnold, Tobias, Justin, and Hang K. Ryu (1997) "Bayesian Method of Moments (BMOM) Analysis of Parametric and Semiparametric Regression Models," Proceedings of the Section on Bayesian Statistical Science, American Statistical Association, 211-216 